\title{
IoT Based Smart Energy Meter System Using Machine Learning
}

\author{
Nelson. $\mathrm{I}^{\mathrm{a}, 1}$, Annadurai. $\mathrm{C}^{\mathrm{b}}$, Ramya. $\mathrm{E}^{\mathrm{b}}$, Shivani. $\mathrm{R}^{\mathrm{b}}$ and Mathusathana. $\mathrm{V}^{\mathrm{b}}$ \\ ${ }^{\mathrm{a}, 1}$ Associate Professor, Dept of ECE, SSN College of Engineering, Chennai, India \\ ${ }^{\mathrm{b}}$ Associate Professor, Dept of ECE, SSN College of Engineering, Chennai, India \\ ${ }^{\mathrm{b}} U G$ Scholar, Dept of ECE, SSN College of Engineering, Chennai, India
}

\begin{abstract}
India is the world's third largest producer and third largest consumer of electricity[1]. The per person energy consumption in India in 2019 is $1181 \mathrm{kWh}$ .With increasing demand and value for energy, it has become tedious to keep track of consumption of energy units. Smart Meters can override these difficulties by providing a more appropriate solution which includes accurate billing, better information on energy consumption thus leading to better utilization. These Smart energy meters are beneficial to both the consumer and the supplier. They provide a more efficient solution in determining tariffs for the latter. Internet of Things is an emerging technology and IoT based devices have revolutionized the field of electronics and IT. The proposed project is an Iot Based Smart Energy meter system developed to efficiently manage the energy consumption in households by avoiding wastage ,to provide accurate information to small scale users and to avoid manual meter reading and automate bill data entry process.
\end{abstract}

Keywords. Internet of Things, Smart Energy Meter System, Thingspeak, Machine Learning.

\section{Introduction}

The internet of things (IoT) is a network of interconnected smart devices enabling data transfer i.e. objects that can be identified uniquely and have the ability to collect and transfer data over a network without manual assistance or intervention. These devices interact within themselves as well as the surroundings and act decisively based on various conditions. India's dependency on energy imports can be limited by promoting energy conservation. This calls for a system built keeping the goal in mind and to analyze and thereby control energy consumption .Thus, an integrated IoT smart meter system is an appropriate solution.

\section{Proposed System}

The proposed project is an IoT enabled device which sends meter readings to the server at a fixed time interval using Node MCU. The system features an alerting system,

\footnotetext{
${ }^{1}$ Nelson.I, Associate Professor, Dept of ECE, SSN College of Engineering, Chennai, India.
}

E mail: nelson@gmail.com 
a home automation unit, a forecasting system and an android application. The proposed project aims to pave the way for efficient resource utilization.

\section{Architecture of the system}

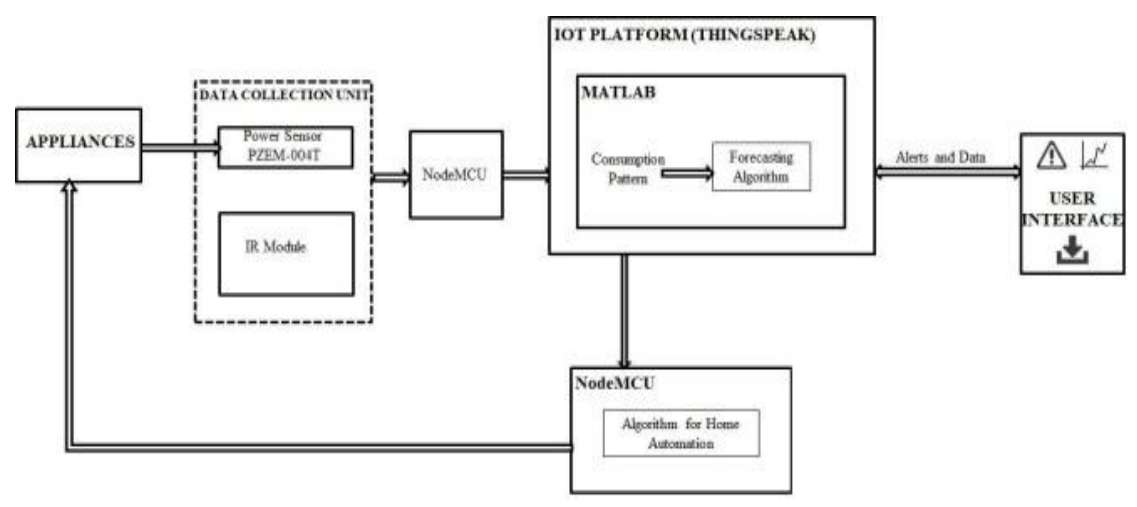

Figure 1. System Block Diagram

The data collection unit comprises the power sensor which is used to measure consumption and a module comprising IR Sensors which we use for the home automation system. Firstly, user's consumption acquired by the power sensor is sent to the NodeMCU. The NodeMCU is used to send the data to the cloud. The consumption pattern is monitored and when it surpasses the thresholds, alerts are sent to the user interface. The consumption pattern is displayed in the form of graphs and significant figures as texts for the user's review. The consumption pattern is also provided as an input for the Forecasting algorithm and the NodeMCU used for the home automation system.The IR Module is utilized for the home automation feature. A pair of IR Sensors are installed in the entrance of each room. The order in which the sensors sense human presence is noted for determining whether the user's entering or leaving the room. This information is sent to the nodeMCU which in turn sends it to the cloud. These values along with the consumption data are sent to the nodeMCU connected to the appliances.

\section{Features of the system}

\subsection{Home Automation}

The purpose of the home automation system is to automate the operation of appliances in order to keep the consumption below the threshold. This feature can function in two modes -Manual mode and Autonomous mode. The algorithm used for home automation takes in the user's consumption, the operational mode of the system, consumption limit for an hour and the presence of an individual in a particular room. The consumption for an hour is estimated from the consumption limit for two months specified by the user. The algorithm checks whether the user's consumption has 
exceeded the threshold estimated. If it did exceed, the system sends an alert to the user and then proceeds to check the operational mode of the system. If the system is in autonomous mode, it checks for the presence of the individual in a room and decides whether to turn the appliances ON/OFF. If the system is in the manual mode, the user can control which appliances need to be turned ON/OFF as per his/her requirement.

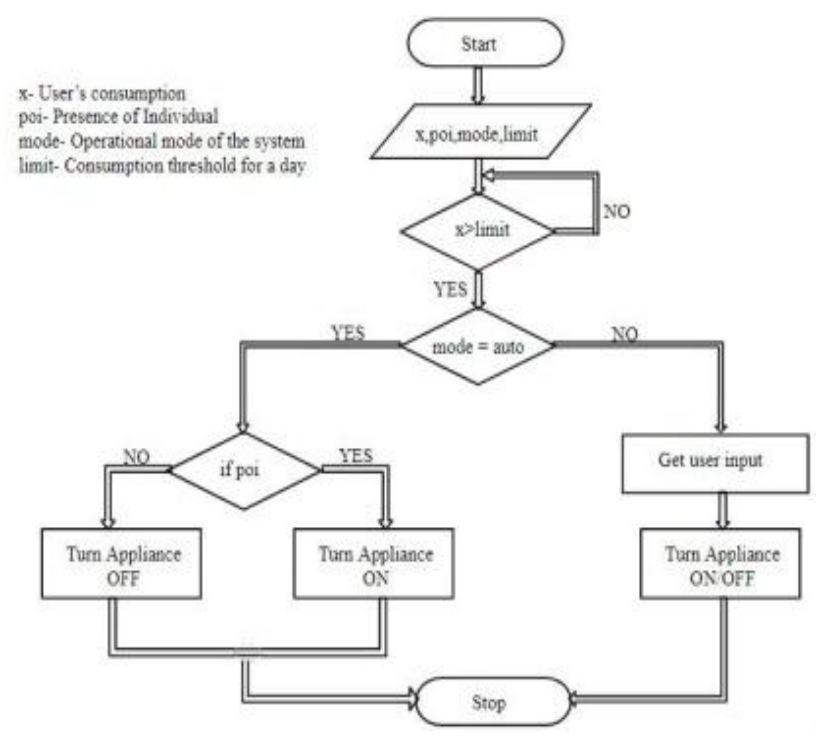

Figure 2. Flowchart of Home Automation algorithm
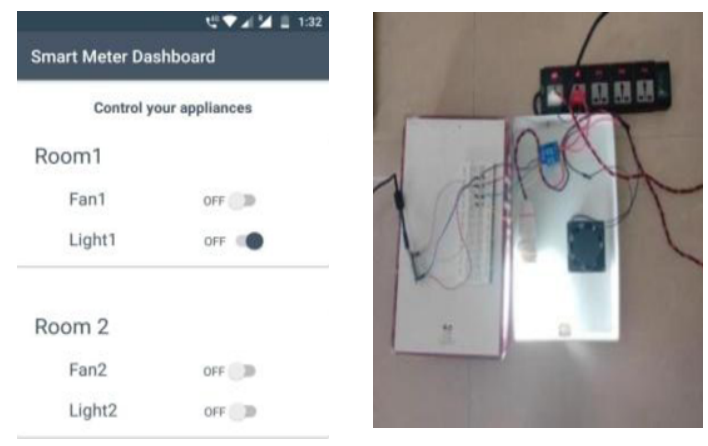

Figure 3. Manual Mode

\subsection{Alerting System}

The system alerts the user when hourly consumption exceeds the hourly threshold calculated and when the overall consumption exceeds 100 units, 200 units and 500 units. The TNEB tariff system has various schemes having different costs per unit of consumption and fixed charges. The first 100 units are of no charge in every scheme. 
When the user's overall consumption exceeds 100 units and is within 200 units, the cost per unit is 1.5 Rs. But when the consumption exceeds 200 units and is within 500 units, for the same 100 units the cost per unit is 2 Rs. This amount can magnify when we consider a bigger scale. Hence by alerting the user when their overall consumption exceeds 100 units, 200 units and 500 units, the system stresses that every unit of consumption plays a vital role.

\subsection{Forecasting System}

The purpose of energy forecasting is to predict future energy consumption and thereby effective energy management. The proposed system incorporates a forecasting model which utilizes the decision tree classifier and predicts energy consumption given a bounded historical data of the consumer and other variables. The variables used in forecasting are Holidays(to distinguish working days and holidays), Past energy consumption, Weather, Temperature of a particular day. With the help of Forecasting, the future consumption of users can be predicted and helps the users plan resources accordingly.

\subsection{Android Application}

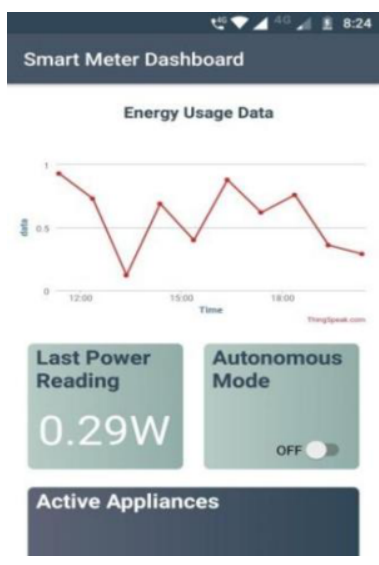

Figure 4. User Interface

The Android Application takes care of retrieving and displaying data to the user and also takes data to the cloud from the user. The purpose of the interface is to make user's interaction simple and efficient. It acts as a medium for two-way communication in cases like controlling appliances, getting consumption threshold as inputs and for displaying consumption patterns and billing details. Consumption data is presented in the form of graphs for better understanding and interpretability.

\section{Conclusion}

Thus, using emerging technologies such as IoT can bring a tremendous amount of change in the utilities sector leading to efficient energy management by providing accurate and reliable information. Hence Smart energy meters paves way for efficient 
resource utilization and uniform distribution in a systematic way which in turn ultimately leads to energy conservation - an urgent necessity.

\section{References}

[1] Arya College, August 2018 Solar Energy Retrieved from: https://aryacollege.org/our-blog/2018/08/

[2] BibekKanti Barman, Shiv NathYadav, Shivam Kumar, SadhanGope. IOT Based Smart Energy Meter for Efficient Energy Utilization in Smart Grid, 2018 2nd International Conference on Power, Energy and Environment:Towards Smart Technology (ICEPE), 2018

[3] Chaudhari S, Rathod.P, A. Shaikh, D. Vora and J. Ahir. Smart energy meter using Arduino and GSM, 2017 International Conference on Trends in Electronics and Informatics (ICEI), Tirunelveli, 2017, pp. 598-601.

[4] Salman siddiq S , S. Reshma , K. Anuja , P. Priyanka, Ch. Karunapravaha Smart Electricity Meter using Wi-Fi, International Journal of Research in Advent Technology, Vol.5, No.3, March 2017 EISSN: 2321-9637.

[5] Swamy M, Pravallika R.Design and implementation of smart energy meter, 2017 International Journal of Innovative Research in Computer and Communication Engineering, Vol. 5, Issue 8, August 2017,ISSN: 2320-9801.

[6] R.Kappagantu, S. Senn, M.Mahesh , S.A.Daniel "Smart grid implementation in India - A case study of Puducherry pilot project”'International Journal of Engineering, Science and Technology Vol. 7, No. 3, 2015, pp. 94-101

[7] Hambali M, Akinyemi A, Oladunjoye J, Yusuf N,(2016): Electric Power Load Forecast Using Decision Tree Algorithms. Computing, Information Systems, Development Informatics \& Allied Research Journal. Vol 7 No 4. Pp 29-42.

[8] Barua A.M, Goswami P.K ,Analysis of Household Electricity Consumption Using Smart Meter Data, International Research Journal of Engineering and Technology Vol. 7, Issue: 8, 2020.

[9] Shukla.R ,Vidhwani.M Prof. V.R. Ghule, Electricity Theft Detection Using Machine Learning ,International Journal of Advance Scientific Research and Engineering Trends,2019-20,Volume 4,ISSN (Online) 2456-0774.

[10] Ambeth Kumar V.D, Precautionary measures for accidents due to mobile phone using IOT, Clinical eHealth, Volume 1, Issue 1, March 2018, Pages 30-35.

[11] Nanagasabapathy.K et.al,,Validation system using smartphone luminescence, IEEE International Conference on Intelligent Computing, Instrumentation and Control Technologies (ICICICT), Pages: 235 - 239, 6-7 July 2017, Kannur, India

[12] Ambeth Kumar V.D; V. D. Ashok Kumar; H. Divakar; R. Gokul, Cloud enabled media streaming using Amazon Web Services, IEEE International Conference on Smart Technologies and Management for Computing, Communication, Controls, Energy and Materials (ICSTM), Pages: 195 - 198, 2-4 Aug. 2017, Vel Tech University, Chennai, India (DOI: 10.1109/icstm.2017.8089150)

[13] Aravindh .Bet.al, .A novel graphical authentication system for secure banking systems, IEEE International Conference on Smart Technologies and Management for Computing, Communication, Controls, Energy and Materials (ICSTM), Pages: 177 - 183, 2-4 Aug. 2017, Vel Tech University, Chennai, India .

[14] Ambeth Kumar V.D et.al, (2016), An Efficient Security System for Data base Management from Illegal Access, IEEE International Conference on Wireless Communications, Signal Processing and Networking (WiSPNET), SSN Engineering College, Chennai, India, 23-25 March, 2016

[15] Ramya,T et.al.,(2014) Personalized authentication procedure for restricted web service access in mobile phones, Applications of Digital Information and Web Technologies (ICADIWT), 2014, Page(s):69 - 74, Bangalore, India (ISBN:978-1-4799-2258-1)

[16] Ambeth Kumar V.D,Saranya,G ,Elangovan.D, RahulChiranjeevi.V, Ashok Kumar V.D, IOT Based Smart Museum Using Wearable Device, Lecture Notes in Networks and Systems, Vol.55, pp: 33-42, 2018

[17] Ambeth Kumar V.D et.al, (2016).An Efficient Security System for Data base Management from Illegal Access, IEEE International Conference on Wireless Communications, Signal Processing and Networking (WiSPNET), SSN Engineering College, Chennai, India, 23-25 March, 2016. 